\title{
The duration of interventricular septal displacement in patients with precapillary pulmonary hypertension as a potential marker of right ventricular dysfunction and pressure overload. A cardiac magnetic resonance study
}

\author{
Sophia-Anastasia Mouratoglou², Alexandros Kallifatidis ${ }^{1 *}$, George Giannakoulas², Julia Grapsa ${ }^{3}$, Georgia Pitsiou ${ }^{4}$, \\ Ioannis Stanopoulos ${ }^{4}$, Stavros Hadjimiltiades ${ }^{2}$, Haralambos Karvounis ${ }^{2}$
}

From 17th Annual SCMR Scientific Sessions

New Orleans, LA, USA. 16-19 January 2014

\section{Background}

Right ventricular (RV) pressure overload results in interventricular septal displacement (IVSD) towards left ventricle in patients with pulmonary arterial hypertension (PAH). There is however scarce data on the duration of IVSD during cardiac cycle as expressed by curvature duration index $(\mathrm{CDi})$ and its potential role in the evaluation of PAH patients. The aim of our study is to reveal the potential value of $\mathrm{CDi}$ as a marker of $\mathrm{RV}$ function and pressure overload.

\begin{abstract}
Methods
All patients underwent cardiac magnetic resonance (CMR, Avanto Siemens 1,5T). A routine set of LV and $\mathrm{RV}$ short-axis cines of $6 \mathrm{~mm}$ slice thickness, were acquired from base to apex using a breath-hold retrospective ECG-gated balanced steady state free precession (SSFP) sequence. CDi (duration of septal curvature configuration $\times 100 /$ cardiac cycle duration), left ventricular eccentricity index in end-systole (LVSei) and end-diastole (LVDei), left ventricular end-systolic (LVESarea) and end-diastolic area (LVEDarea), RV end-systolic (RVESarea) and end diastolic area (RVEDarea) were defined in the short-axis view in the level of papillary muscles. Interventricular septal curvature ratio (CR) was defined in the same level, at end-systole. The right ventricular wall thickness (RVWT) was assessed in the anterior
\end{abstract}

${ }^{1}$ Department of Radiology, St. Luke's Hospital, Thessaloniki, Greece Full list of author information is available at the end of the article segment of RV. Tricuspid annular plane systolic excursion (CMR-TAPSE) was defined in the 4-chamber view. Right ventricular ejection fraction (RVEF) and RV endsystolic volume (RVESV) and end-diastolic volume (RVEDV) were obtained with the use of serial short axis cine-MRI views from base to the apex, according to Simpson's rule.

\section{Results}

Our study included 41 consecutive patients (33 women, mean age $45.6 \pm 12.1$ years) with precapillary pulmonary hypertension (29 with idiopathic PAH, 7 with PAH associated to congenital heart disease, 2 with PAH associated to connective tissue disease and 3 with chronic thromboembolic pulmonary hypertension). A direct linear correlation between CDi and CMR-TAPSE ( $\mathrm{r}=$ -0.464, $p=0.02), C R(r=-0.796, p<0.001)$, LVSei $(r=$ $0.802, \mathrm{p}<0.001)$ and LVDei $(\mathrm{r}=0.6, \mathrm{p}<0.001)$, LVESarea $(-0.364, \mathrm{p}=0.02)$, LVEDarea $(-0.538, \mathrm{p}<0.001)$, RVEF $(-0.484, \mathrm{p}=0.02)$, RVESV $(0.509, \mathrm{p}=0.01)$, RVESarea (0.538, $\mathrm{p}<0.001)$, RVEDarea $(0.497, \mathrm{p}=0.02)$, RVWT $(0.447, \mathrm{p}=0.004)$ was observed.

\section{Conclusions}

$\mathrm{CDi}$ is a potential non invasive simple marker for the evaluation of RV pressure overload and function in patients with precapillary pulmonary hypertension. Its prognostic significance remains to be established in further studies. 
Table 1

\begin{tabular}{cccc}
\hline \multicolumn{5}{c}{ Bivariate correlation } \\
\hline & mean \pm SD & $\mathbf{r}$ & $\mathbf{p}$ \\
\hline CDi\% & $68.2 \pm 23.5$ & & \\
\hline CMR-TAPSE $(\mathrm{cm})$ & $1.46 \pm 0.45$ & -0.464 & 0.02 \\
\hline CR & $0.61 \pm 0.19$ & -0.796 & $<0.001$ \\
\hline LVSei & $1.96 \pm 0.84$ & 0.802 & $<0.001$ \\
\hline LVDei & $1.47 \pm 0.30$ & 0.6 & $<0.001$ \\
\hline LVESarea & $13.98 \pm 5.35$ & -0.364 & 0.02 \\
\hline LVEDarea & $27.49 \pm 7.44$ & -0.538 & $<0.001$ \\
\hline RVEF & $47.67 \pm 11.21$ & -0.484 & 0.02 \\
\hline RVESV & $64.12 \pm 37.44$ & 0.509 & 0.01 \\
\hline RVESarea & $24.29 \pm 10.38$ & 0.538 & $<0.001$ \\
\hline RVEDarea & $34.86 \pm 9.70$ & 0.497 & 0.02 \\
\hline RVWT & $0.65 \pm 1.18$ & 0.447 & 0.004 \\
\hline
\end{tabular}

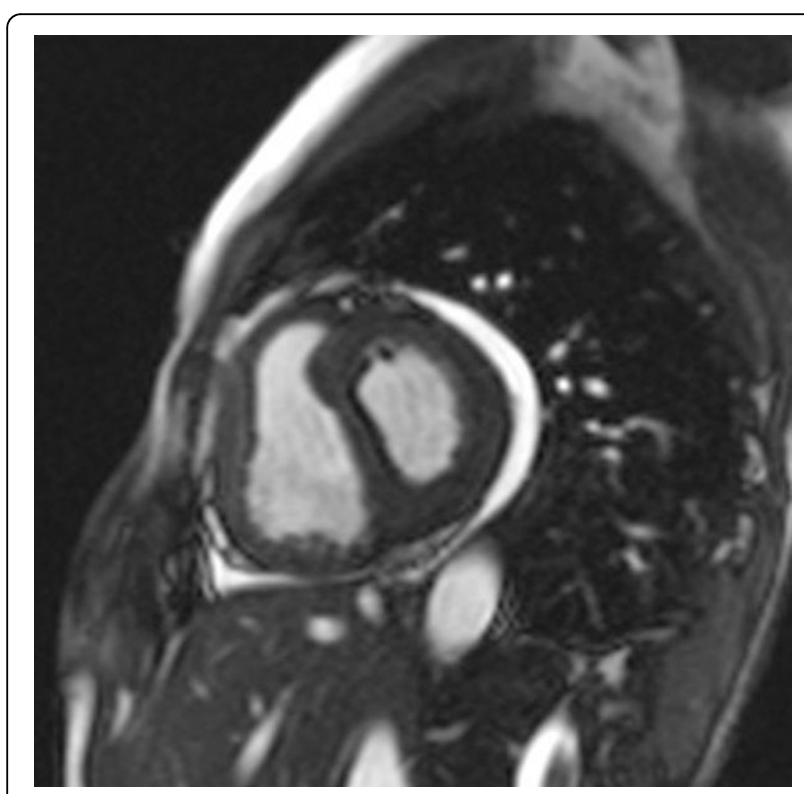

Figure 1 Basal Short-Axis SSFP image in end-systolic phase showing leftward septal displacement.

\section{Funding}

Hellenic Cardiological Society.

\section{Authors' details}

'Department of Radiology, St. Luke's Hospital, Thessaloniki, Greece.

${ }^{2}$ 1st Department of Cardiology, Aristotle University of Thessaloniki, AHEPA University Hospital, Thessaloniki, Greece. ${ }^{3}$ Department of Cardiovascular Sciences, Hammersmith Hospital, Imperial College NHS Trust, London, UK. ${ }^{4}$ Respiratory Failure Unit, Aristotle University of Thessaloniki, G. Papanikolaou Hospital, Thessaloniki, Greece.

Published: 16 January 2014

\section{doi:10.1186/1532-429X-16-S1-P240}

Cite this article as: Mouratoglou et al:: The duration of interventricular septal displacement in patients with precapillary pulmonary

hypertension as a potential marker of right ventricular dysfunction and pressure overload. A cardiac magnetic resonance study. Journal of

Cardiovascular Magnetic Resonance 2014 16(Suppl 1):P240.

\section{Submit your next manuscript to BioMed Central and take full advantage of:}

- Convenient online submission

- Thorough peer review

- No space constraints or color figure charges

- Immediate publication on acceptance

- Inclusion in PubMed, CAS, Scopus and Google Scholar

- Research which is freely available for redistribution

Submit your manuscript at www.biomedcentral.com/submit 